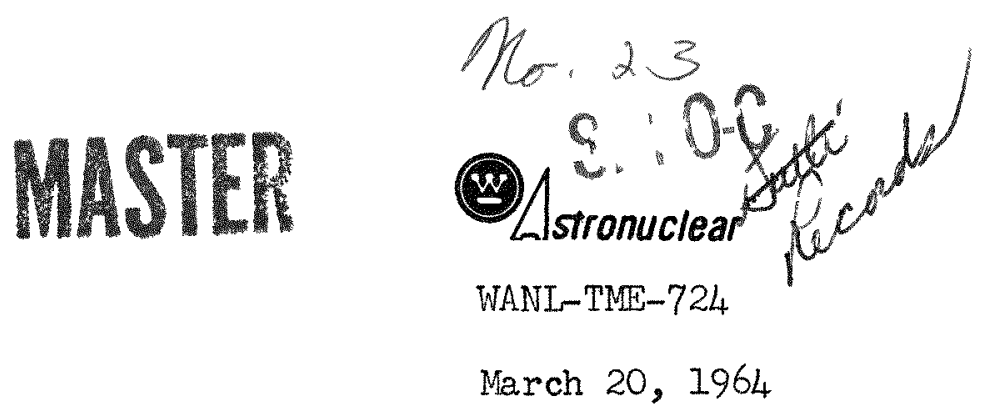

32

\title{
LEAKAGE FLOW OF PLUGGED-ORIFICE GRAPHITE FUEL ELEMENTS AT REACTOR OPERATING PRESSURES
}

(Title Unclassified)

$$
\text { By }
$$

E. H. Schulman

Fluid Flow Laboratory

4 Experimental Engineering Department

\section{NOTICE}

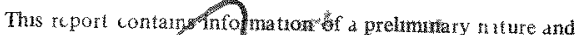

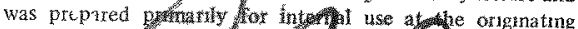

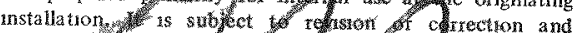

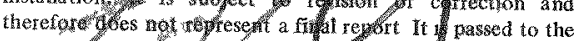

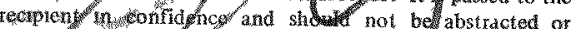

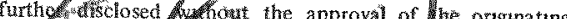
insthation of USERDA Technical mformatr gefiter Oak Ruge IN 37830

Approved By:

Classification cancelled loredrat to
by authority of

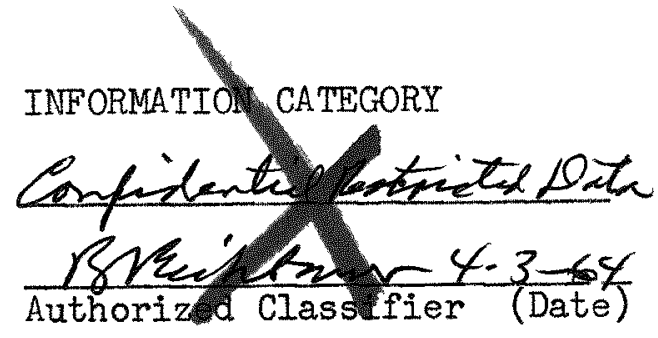

by $4,2,0$, TIG mate

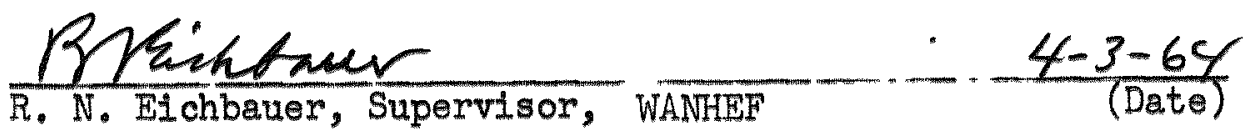

Fluid Flow Laboratory

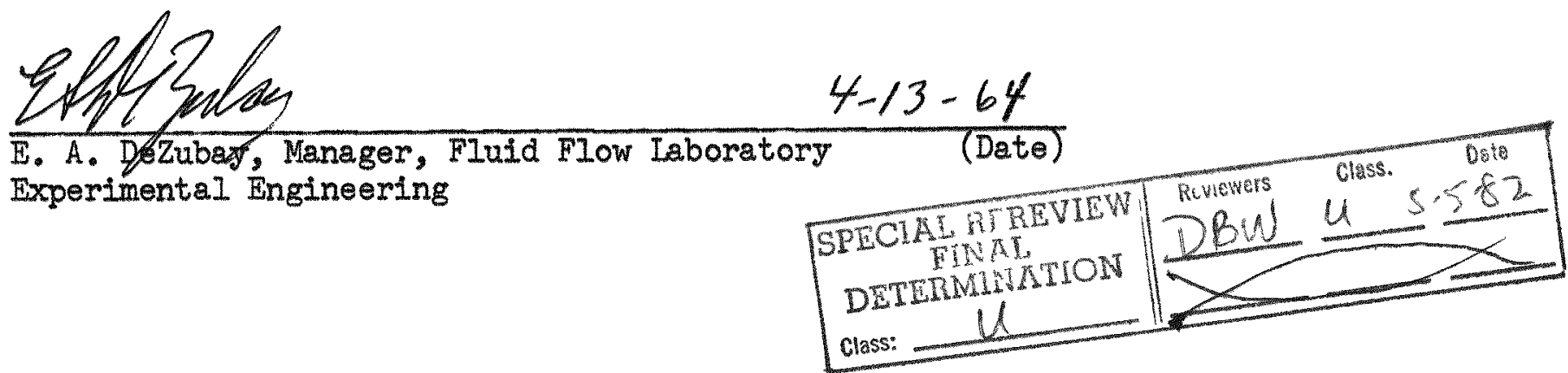

OISTRBBUTION OE THIS DOCUMENT IS UNLMITED 


\section{DISCLAIMER}

This report was prepared as an account of work sponsored by an agency of the United States Government. Neither the United States Government nor any agency Thereof, nor any of their employees, makes any warranty, express or implied, or assumes any legal liability or responsibility for the accuracy, completeness, or usefulness of any information, apparatus, product, or process disclosed, or represents that its use would not infringe privately owned rights. Reference herein to any specific commercial product, process, or service by trade name, trademark, manufacturer, or otherwise does not necessarily constitute or imply its endorsement, recommendation, or favoring by the United States Government or any agency thereof. The views and opinions of authors expressed herein do not necessarily state or reflect those of the United States Government or any agency thereof. 


\section{DISCLAIMER}

Portions of this document may be illegible in electronic image products. Images are produced from the best available original document. 


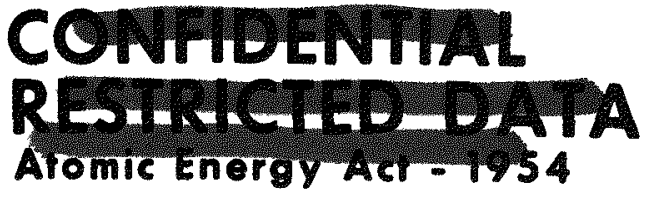

竬曼

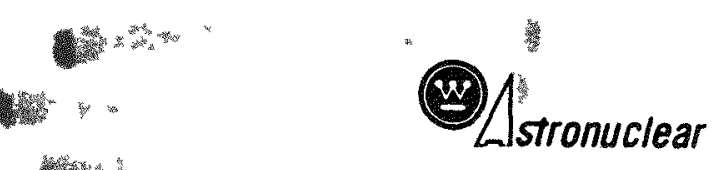

3.
WANL-TME-72/4

March 20, 1964

\section{SUMMARY}

Leakage flow rates, for the ND 207 reactor, occurring through the end faces of plugged-orifice graphite fuel elements, were estimated to be of the order of $6.84 \times 10^{-5}$ Ibs/sec to $76.0 \times 10^{-5} \mathrm{lbs} / \mathrm{sec}$. These leakage flow would occur at the following ND 207 reactor operating condition,
a. Inlet core pressure $=750$ psia
b. Exit core pressure $=620 \mathrm{psia}$
c. Ambient temperature
d. Inlet inner reflector mass flow rate $=1 / 2 \mathrm{lb} / \mathrm{sec}$

These pressure conditions will not be exceeded during the ND 207 tests. Based on inner reflector mass flow, leak rates are estimated to be from $0.014 \%$ to $0.15 \%$ of ND 207 reactor flows.

Discrepancies existing between this report and IASI report N-3-1607 entitled, "Measurement of KIWI-B-4 Cluster Flow and Pressure Drop", may be attributed to differences in experimental technique and physical configuration. 
Confribermat

RESTRICTED DATA

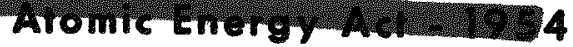

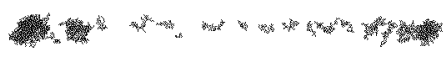

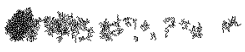

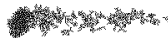

Wstronuclear

WANI-TME 724

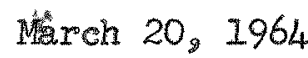

INTRODUCTION

Confirmation of leakage flows through the end faces of cold flow, plugged-orifice fuel elements of the type used in the ND 207 reactor is necessary to lend confidence to measured element interstitial flows. Leakage tests performed on several elements at low pressure are extended to reactor operating conditions. Comparison is made between these results and those reported in IASI report N-3I607 entitled, "Measurement of KIWI-B 4, Cluster Flow and Pressure". A brief description of the test apparatus and procedures is a.so included. 

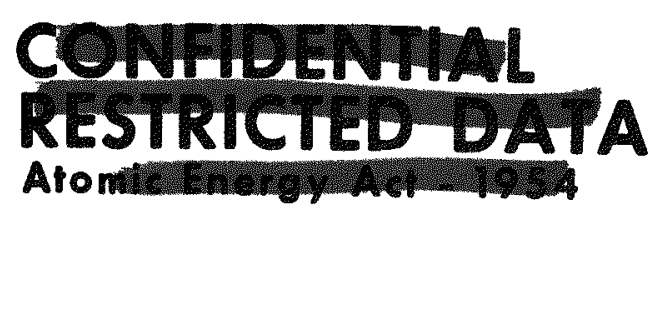

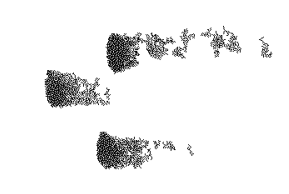

(6) Istronuclear

WANI-TME-724

March 20, 1964

\section{DESCRIPTION OF TEST APPARATUS AND PROCEDURE}

The test fixture used is shown in detail on WANL drawing NT 40086 entitled, "Orifice Leak Test Fixture", and schematically in Figure 1. A transient method of testing was employed to determine the flow through a plugged-orifice graphite fuel element. Plugged-orifice elements which had been inspected, tested, and found acceptable for reactor use were inserted, at the plugged end, in the test fixture plenum. An inflatable trube, pressurized to $125 \mathrm{psig}$, sealed the fuel element in place. The test fixture plenum was then pressurized. Any subsequent decrease in plenum pressure represented a decrease of mass in the plenum.

A series of tests were performed in which ambient hydrogen gas was used to pressurize the test fixture plenum. Test elements were inserted into the fixture after a thin layer of vacuum grease had been applied to the surfaces on which the inflatable tube would seat. Care was taken that no vacuum grease contaminate the end surface of the element.

The system was leak checked by inserting a solid plece of aluminum, of the same configuration as a test element, in the test fixture. The system was leak tight since no loss of plenum pressure was observed at the end of a twenty minute period. The pressure was read on a Heise gage graduated to one-tenth of a psi.

Elements were tested at plenum pressures as high as 90 psig. The element leak rate was determined by observing the change in plenum pressure with time. The mass flow rate was then determined by the following expression for isothermal flow. Element leakage flow $=\frac{\mathrm{V}}{\mathrm{RT}} \frac{\mathrm{dp}}{\mathrm{dt}}$

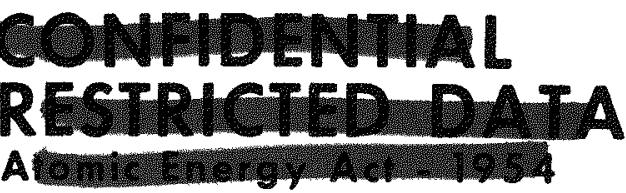




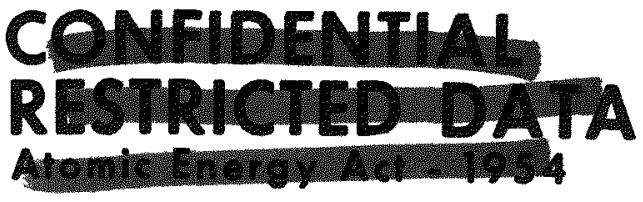

(4)

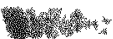

WANL-TME-724

Ilarch 20, 1964

\#1 Test Element 7

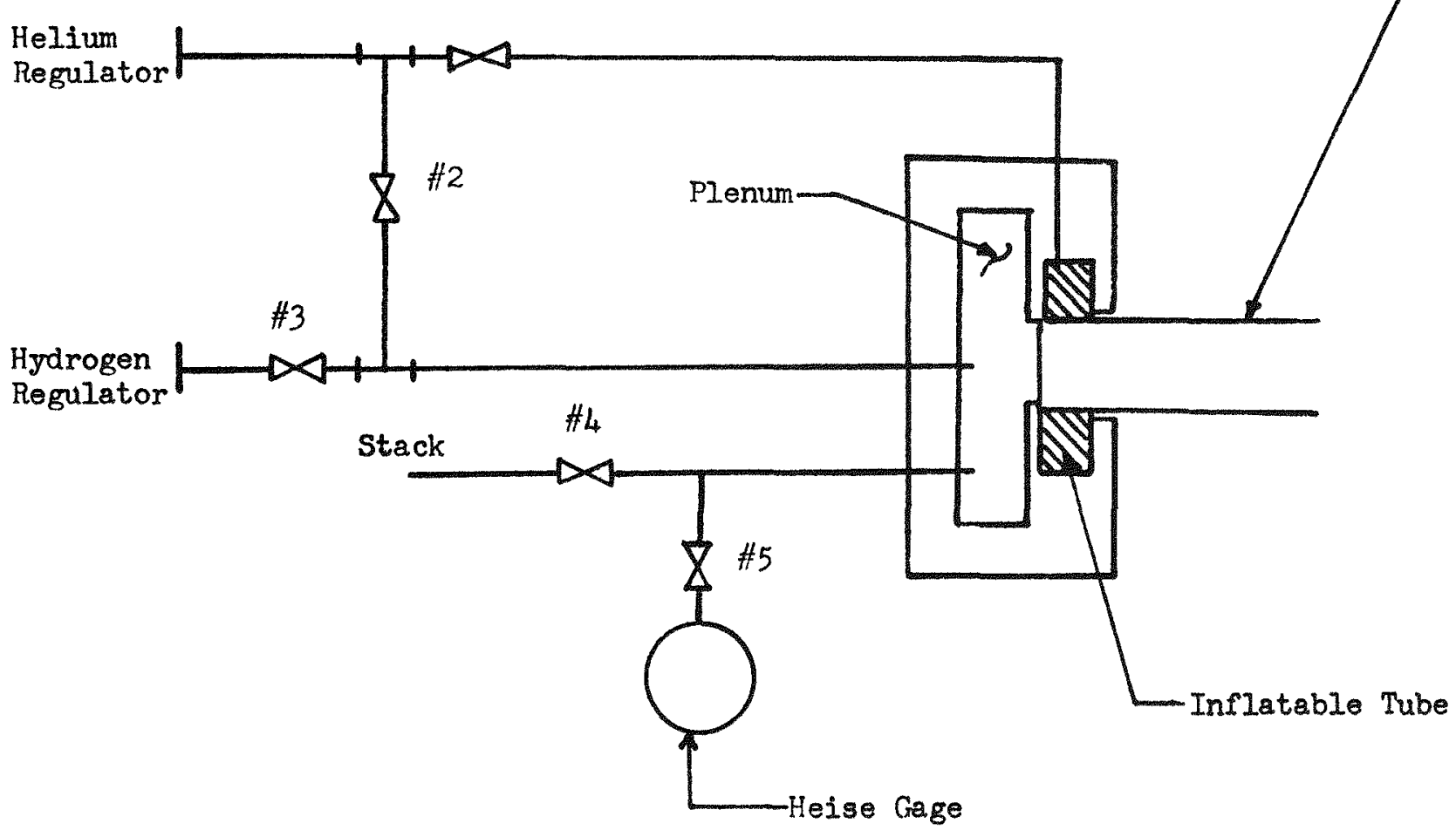

SCHEMATIC ORIFICE LEAK TEST FIXTURE

AND ASSOCIATED CONTROL SISTEM

FIGURE I 
Test data is reproduced in graphical form in Appendix B. The maximum hydrogen mass flow rate was achieved under the following conditions:

Plenum Pressure $=90 \mathrm{psig}$
Ambient Pressure $=15 \mathrm{psia}$
Ambient Temperature $=520^{\circ} \mathrm{R}$

For a plenum volume of 15 cubic inches,

$$
\begin{aligned}
\text { element leakage flow } & =\frac{V}{\mathrm{RT}} \frac{\mathrm{dp}}{\mathrm{dt}} \\
& =2.40 \times 10^{-8} \mathrm{Ibs} / \mathrm{sec}-\text { element }
\end{aligned}
$$

Note that several elements exhibited no observable leakage for the 20 minute test interval. 

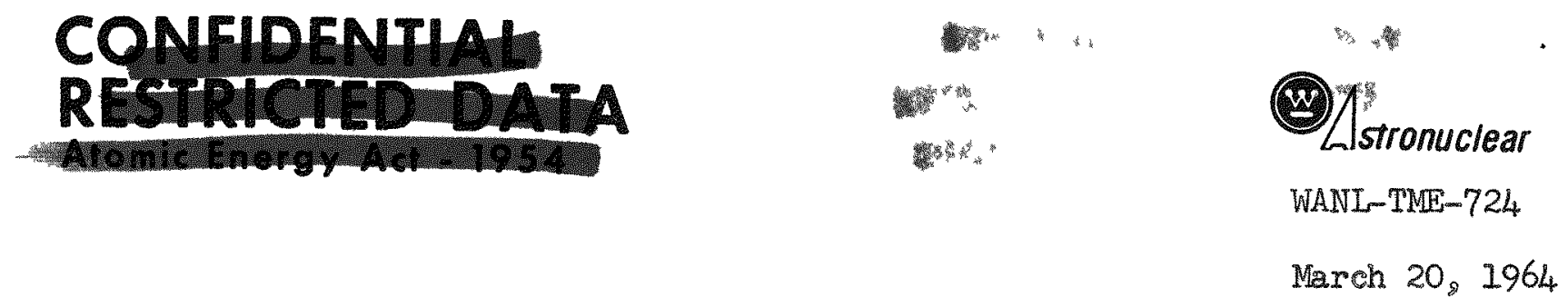

\section{ANALISIS}

There are two ways in which element leakage flow might occur through a pluggedorifice fuel element. These are:

1. Flow through the element due to graphite permeability。

2. Flow past the plugged orifice due to a defective orifice-element seal. The sum of these two flows is the "element leakage flow".

The leakage flow due to graphite permeability was found to be negligible. This is shown by the fact that several elements tested had no detectable leakage flow. The apparent impermeability of the end of the graphite element was due to the fact that the plugged-orifices and adhesive used in cementing the plugged-orifice in place covered the majority of the end face of the element, leaving very little graphite exposed (see Figure 2). In addition, the sealing arrangement aromd the element was such as to allow no gaseous diffusion through the sides of the element. It is concluded that, for the test arrangement used, the only significant leakage was due to defective orifice-element sealing。

The extrapolation of experimental data to reactor operating conditions requires the formulation of a realistic flow model. Examination of experimental results did not help determine the particular type of flow which exists. Three analytical models which are probable are:

1. Laminar flow

2. Turbulent flow

3. Orifice flow

Any of the above types of flow might exist, singularly or concurrently, dependent on the particular nature of the orifice-element seal defect and the reactor operating

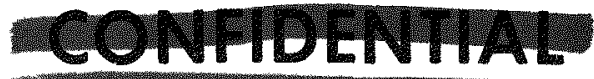

RESTRTELOUDATA

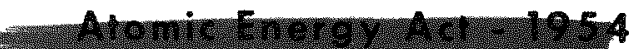

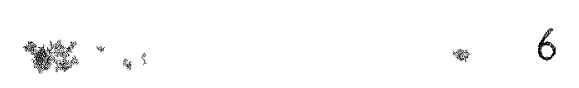

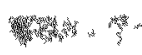

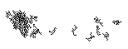



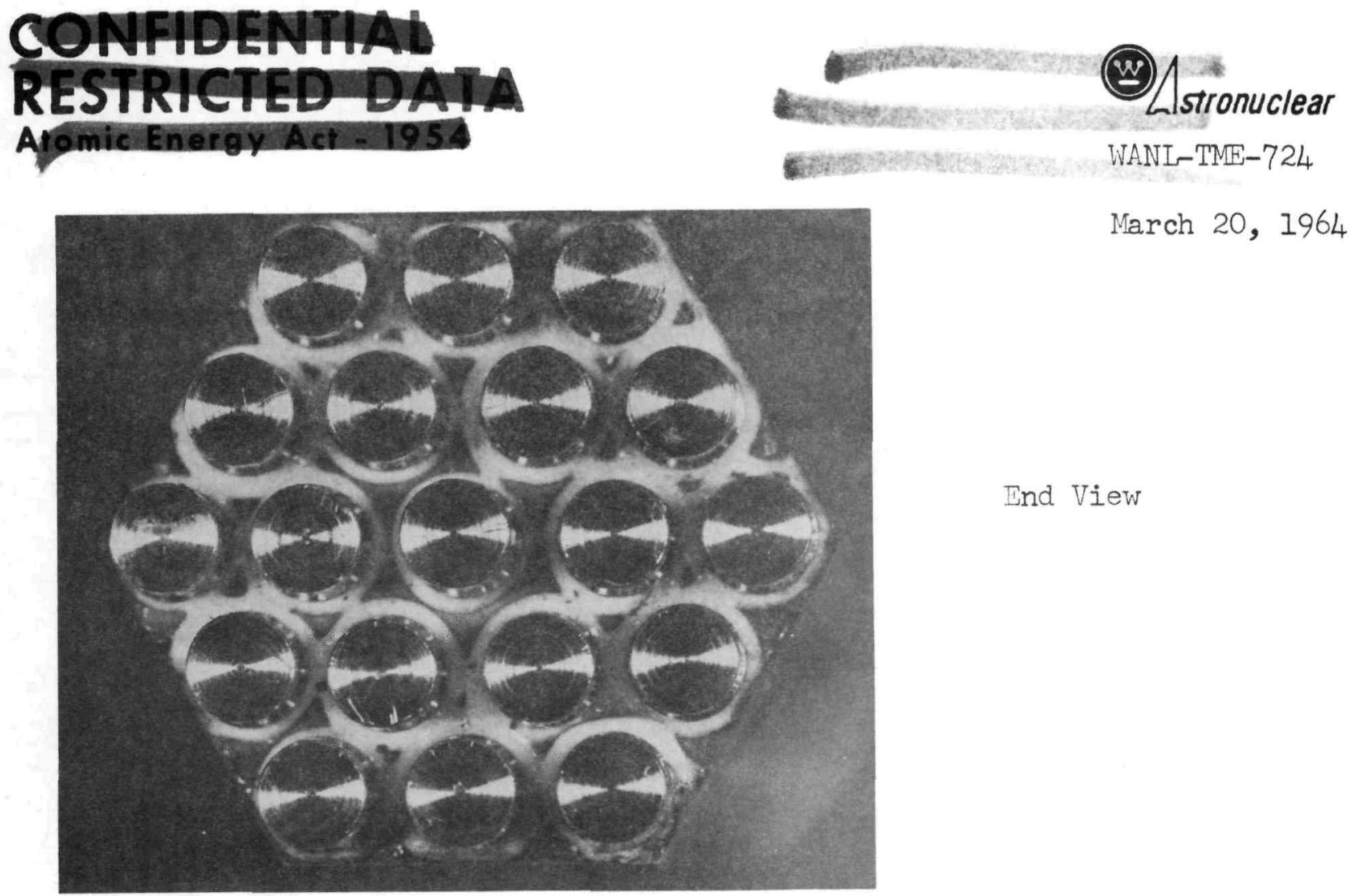

March 20, 1964

End View

Oblique View

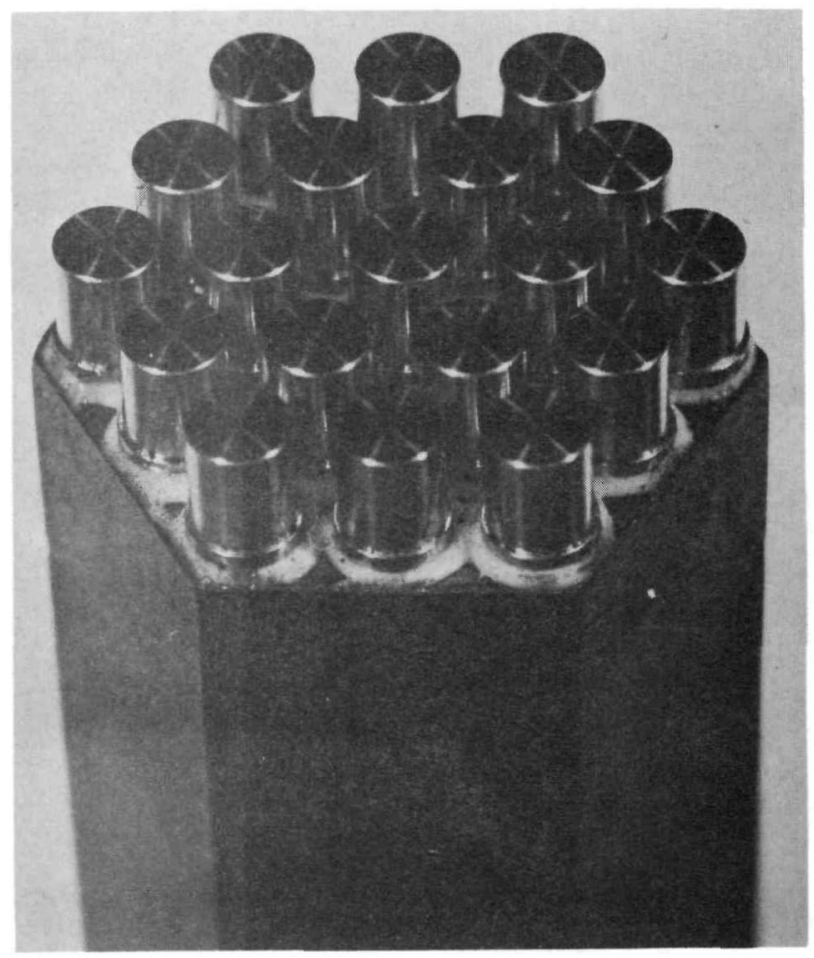

PHOTOS OF PLUGGED END OF GRAPHITE ELMMENTS

FIGURE 2

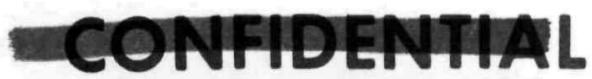

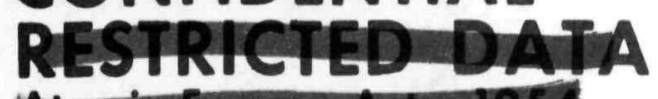

Atomie Energy Act-1954 

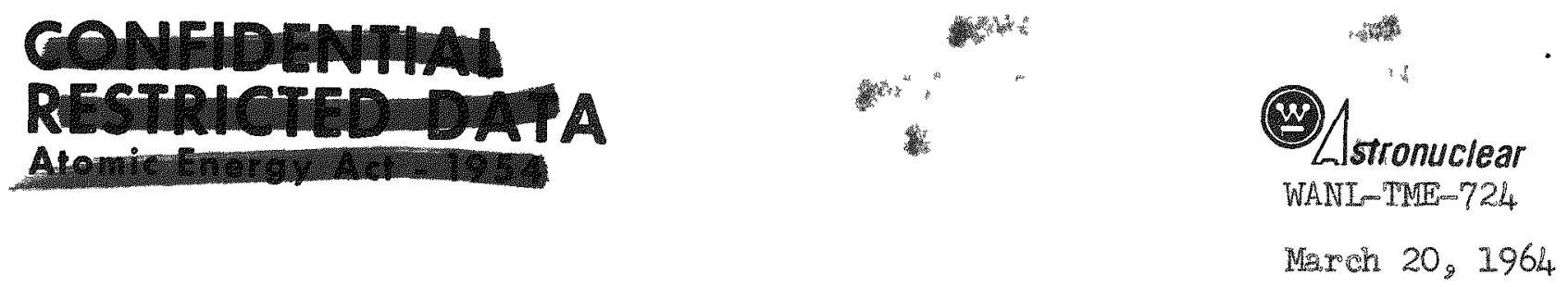

conditions. Rather than attempt to find the rature of the flow oamring. or the percentage of flows occurring in several simltaneous regines, 11 posible plow regines were considered as if they existed singly. In this manners the roange of mas flow rates can be calculated and the order of magnitude of leakage estimated.

1. Laminar Flow

A laminar fow condition s charateriged by the following relation:

$W \propto p_{0}-p$

Rearranging terms and adding a constart of proportionality

$$
W=K p_{0}\left[1-\frac{p}{p_{0}}\right]
$$

The constant of proportionality is determined from one of the experimental conditions

$$
\begin{aligned}
W & =2.40 \times 10^{-8} \mathrm{Lbs} / \mathrm{sec}-\text { element } \\
\mathrm{p}_{0} & =105 \mathrm{psia} \\
\mathrm{p} & =15 \mathrm{psia} \\
\mathrm{K} & =\frac{W}{\mathrm{p}_{0}\left[1-\frac{\mathrm{p}}{\mathrm{p}_{0}}\right]}=\frac{2.40 \times 10^{-8}}{105\left[1-\frac{15}{205}\right]}
\end{aligned}
$$

${ }^{1} p_{0}$ is taken to be the inlet to core condition. It is obvious that the approach velocity to the core is regligible, thereby sabstantiating this assumption. 


$$
\mathrm{K}=2.665 \times 10^{-10} \frac{\mathrm{Ibs} / \mathrm{sec}}{\mathrm{psia}}
$$

The results of extending the experinental results to various reactor operating conditions is shown in Figure 3.

2. Turbulent Flow

Turbulent flow is characterized by the following relation:

$$
w \propto p_{0}^{2}-p^{2}
$$

Rearranging terms and inserting a constant of proportionality:

$$
W=K p_{0}^{2}\left[I-\left(\frac{p}{p_{0}}\right)^{2}\right]
$$

The constant is solved

$$
\begin{aligned}
& K=\frac{W}{p_{0}^{2}\left[1-\left(\frac{p}{p_{0}}\right)^{2}\right]} \\
& K=2.225 \times 10^{-12} \frac{\mathrm{Ibs} / \mathrm{sec}}{(\mathrm{psia})^{2}}
\end{aligned}
$$

Extension of these results to various reactor operating conditions is shown in Figure 4 \% 
3. Orifice F10w

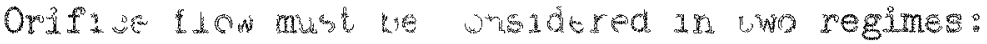

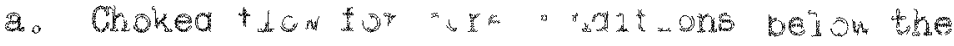

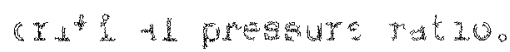

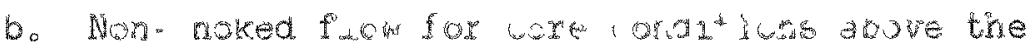

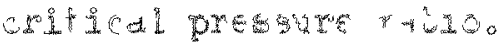

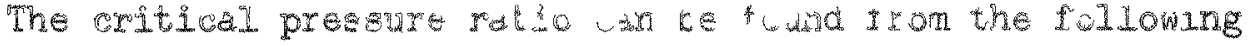

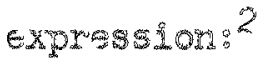

$$
\frac{p^{3}}{p}=\left[\frac{k+1}{2}\right]^{\frac{k}{k}}
$$

for hydrogen $k=1.4$

$$
\text { and } \frac{e^{2}}{p}=0.528
$$

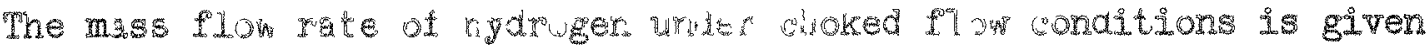
by

$$
\frac{W \sqrt{T}}{A}=0.94
$$

and vader nor-ohomed condition oy

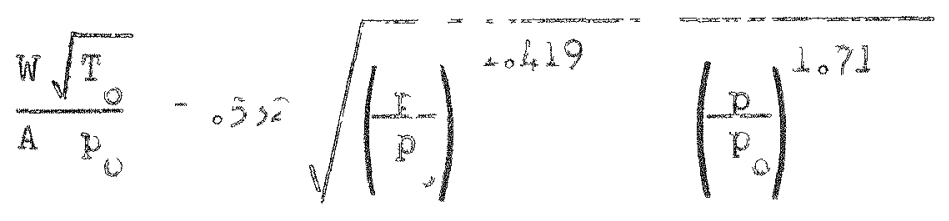

The deritratiun of this and the way Appendix $\mathrm{C}$.

CONPIOENTTAL

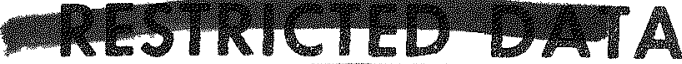

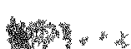
10

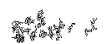

位 
A rapid calculation of experimental conditions shows that all tests were conducted in the choked flow region. An equivalent orifice area can be calculated from a knowledge of the experimental flow rates and operating conditions.

$$
\begin{aligned}
& A=\frac{W \sqrt{T_{0}}}{.1391 \mathrm{p}_{0}}=\frac{2.40 \times 10^{-8} \mathrm{lbs} / \mathrm{sec} 530^{\circ} \mathrm{R}}{.1391 \times 1.511 \times 10^{4} \mathrm{psfa}} \\
& A=2.63 \times 10^{-10} \mathrm{ft}^{2}
\end{aligned}
$$

Mass flow rates fer ali reator operating conditions may now be caloulated using the appropriate equations in the proper regions. The following constarts were used for the calculations presented in Figure 5.

$$
\begin{aligned}
& T_{0}=5300 \mathrm{R} \\
& A=2.63 \times 10^{-10} \mathrm{ft}^{2}
\end{aligned}
$$



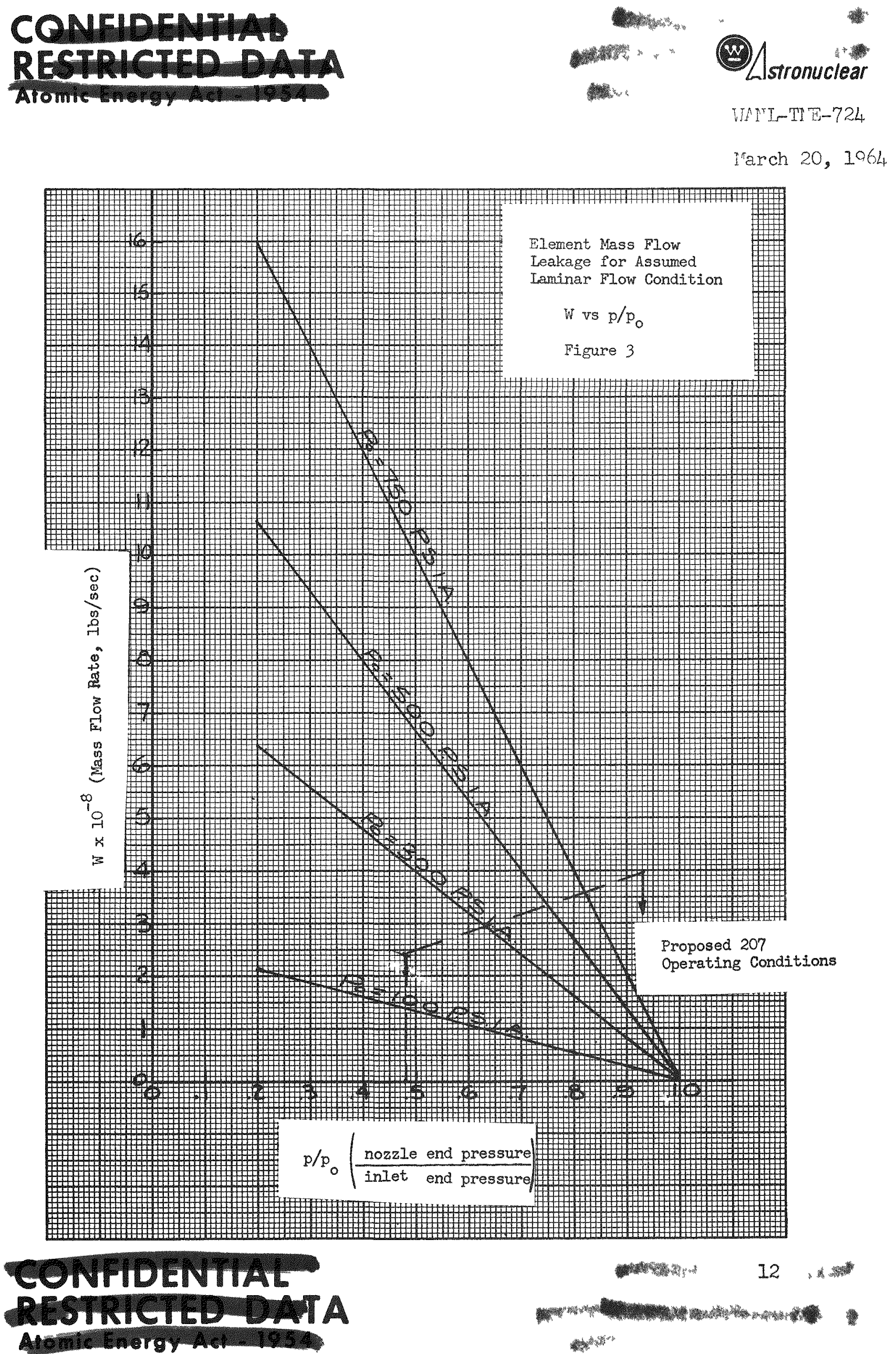


\section{CONFIDENTTAZ RESTRICTED DATA (1)}

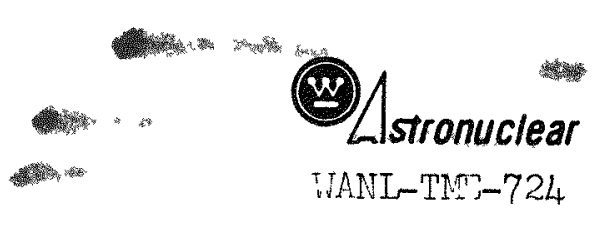

March 20, 1964

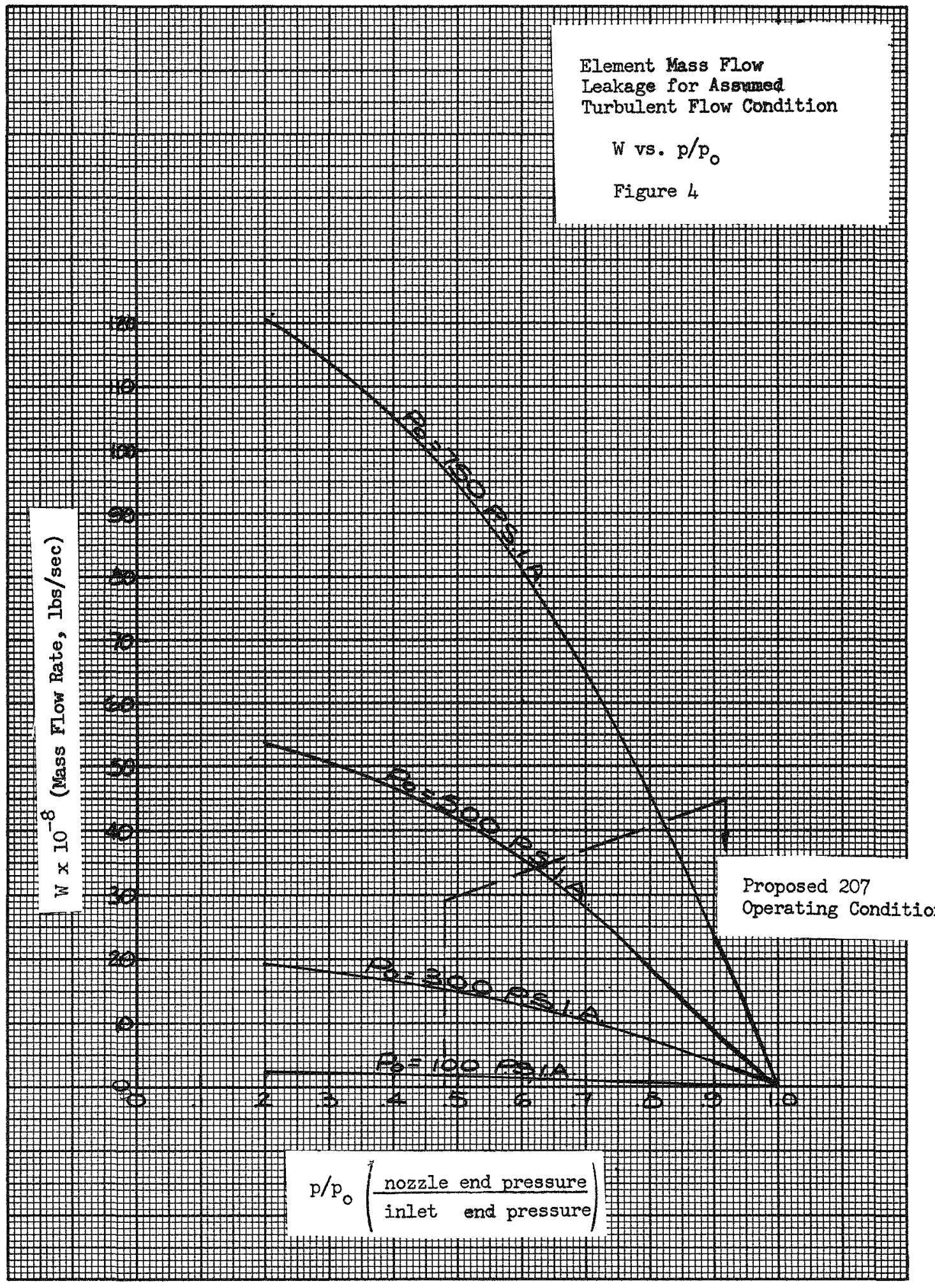

CONFIDENTUA
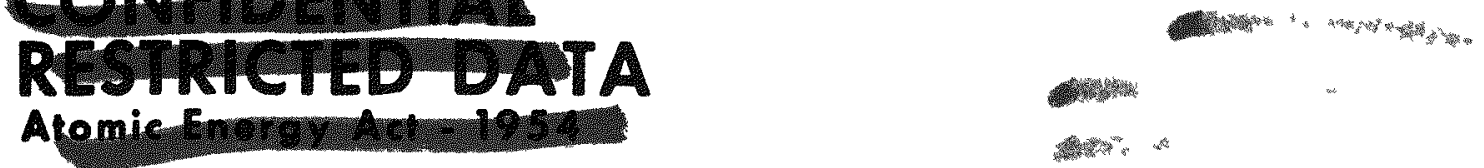

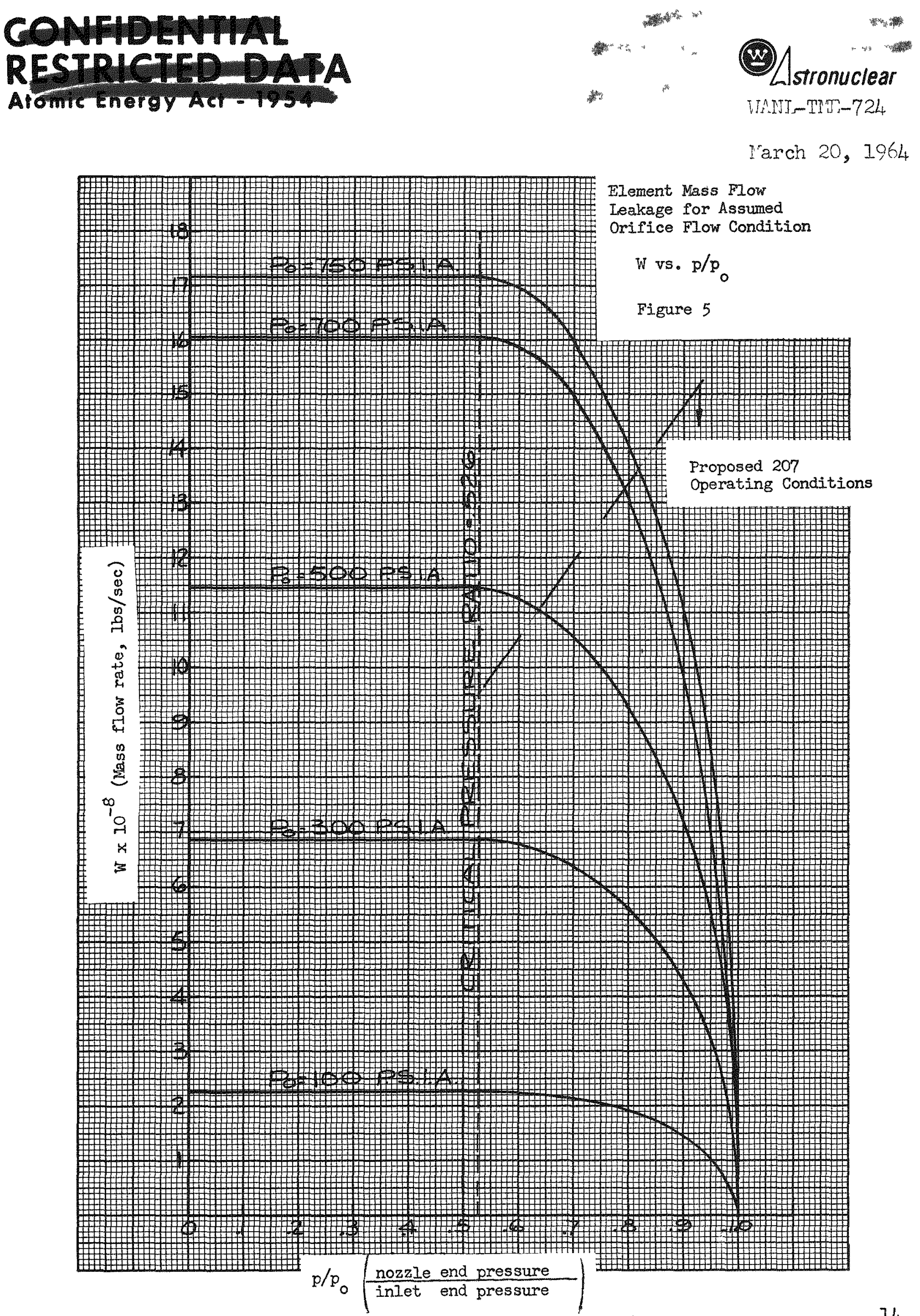


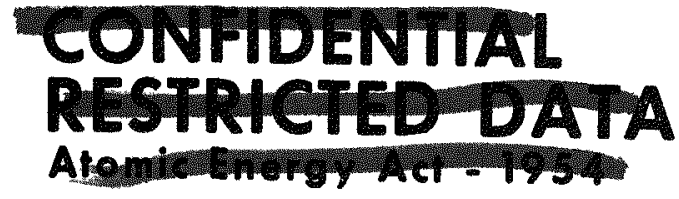

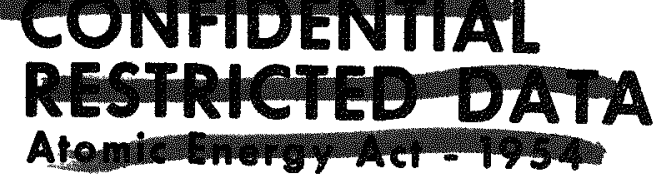

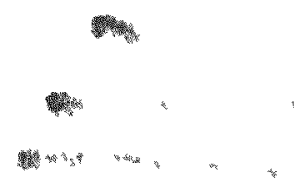

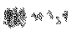

Istronuclear

WANL-TME-724

March 20, 1964

\section{DISCUSSION AND COMPARISON OF RESULTS}

The techniques used in installing and testing the plugged orifices in graphite fuel elements are described in Appendix. D. Leakage tests were performed on all elements, in order to insure that all plugged orifices were properly installed. The discovered techniques and testing requirements evolved through an organized program when it was discussed, at the outset of element fabrication, that plugged orifices leaked excessively.

The results of calculations presented in Figures 3, 4 and 5 are the estimated mass flow rates for the three postulated flow conditions occurring in a single plugged graphite fuel element. Assuming that all 1900 elements, including the non-fuel graphite elements, leak at the same rate, the mass flow rates for a single element can be converted to an equivalent reactor flow rate. The flow rates are shown in the following table based on the worst element tested ${ }^{3}$ for the three postulated flow regimes.

${ }^{3}$ This particular element was compared with a random sampling of 50 elements which had been used in the construction of the ND 20701 reactor. The leakage flow into each element flow channel was recorded by observing the increase in pressure, from atmospheric, in a 5 second interval (see Appendix D). The percentage of flow channels leaking at each rate is recorded below for the random sampling and for the particular element tested.

\begin{tabular}{|c|c|c|c|c|c|c|c|}
\hline Pressure & Increase in 5 Seconds (psi) & 8.05 & $\begin{array}{c}.06 \text { to } \\
.15\end{array}$ & $\begin{array}{c}.16 \text { to } \\
.25\end{array}$ & $\begin{array}{c}.26 \text { to } \\
.35\end{array}$ & $\begin{array}{c}.36 \text { to } \\
.45\end{array}$ & 3.46 \\
\hline Per Cent & $\begin{array}{l}\text { of Flow Channels Leaking } \\
\text { Random Sample }\end{array}$ & $68 \%$ & $18 \%$ & $5.5 \%$ & $.4 \%$ & $.1 \%$ & 0 \\
\hline & Worst Test This Experiment & $79 \%$ & $21 \%$ & 0 & 0 & 0 & 0 \\
\hline
\end{tabular}

It is seen that this element is in relatively good agreement with the statistical profile of elements used in the ND 20701. 

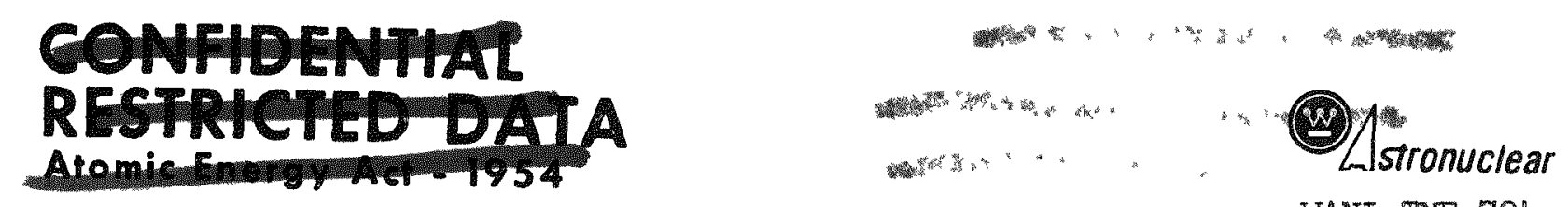

WANI-TME-724

March 20, 1964

$$
\begin{aligned}
& \text { Assumed Flow Condition } \\
& \mathrm{p}_{0}=750 \text { psia } p=620 \text { psia }
\end{aligned}
$$

Laminar Flow

Turbulent Flow

Orifice Flow
Element Mass Flow Leak Rate

$3.6 \times 10^{-8} \mathrm{Ibs} / \mathrm{sec}$

$40 \times 10^{-8} \mathrm{Ibs} / \mathrm{sec}$

$13.5 \times 10^{-8} 1 \mathrm{bs} / \mathrm{sec}$
Reactor Mass Flow

Leak Rate

$6.84 \times 10^{-5} \mathrm{Ibs} / \mathrm{sec}$

$76.0 \times 10^{-5} \mathrm{Ibs} / \mathrm{sec}$

$25.6 \times 10^{-5} 1 \mathrm{bs} / \mathrm{sec}$

s

For the above listed core pressure conditions the flow rates for the ND 207 reactor is estimated at $\frac{1}{2} \mathrm{Ib} / \mathrm{sec}$. Maximum estimated leakage flow through the end faces of the plugged-graphite elements is $76.0 \times 10^{-5} \mathrm{Ibs} / \mathrm{sec}$ or less than $0.15 \%$ of 207 reactor flow, for a turbulent flow condition. Laminar flow and orifice flow give percentage figures of $.014 \%$ and $.052 \%$ respectively at the same core pressure conditions.

Comparison of this data with that presented by IASL report N-31607 shows large discrepancies in results. Close examination of the two experiments revealed the following differences:

a. The seals preventing fluid leakage past the side of the graphite fuel element were located in different places (see Figure 7). WANL sealing arrangement was such that only the end face of the graphite fuel element was exposed to fluid pressure. IASL sealed its elements approximately 2 inches back of the end face, thereby, allowing the sides of its elements to leak fluid due to graphite porosity. 


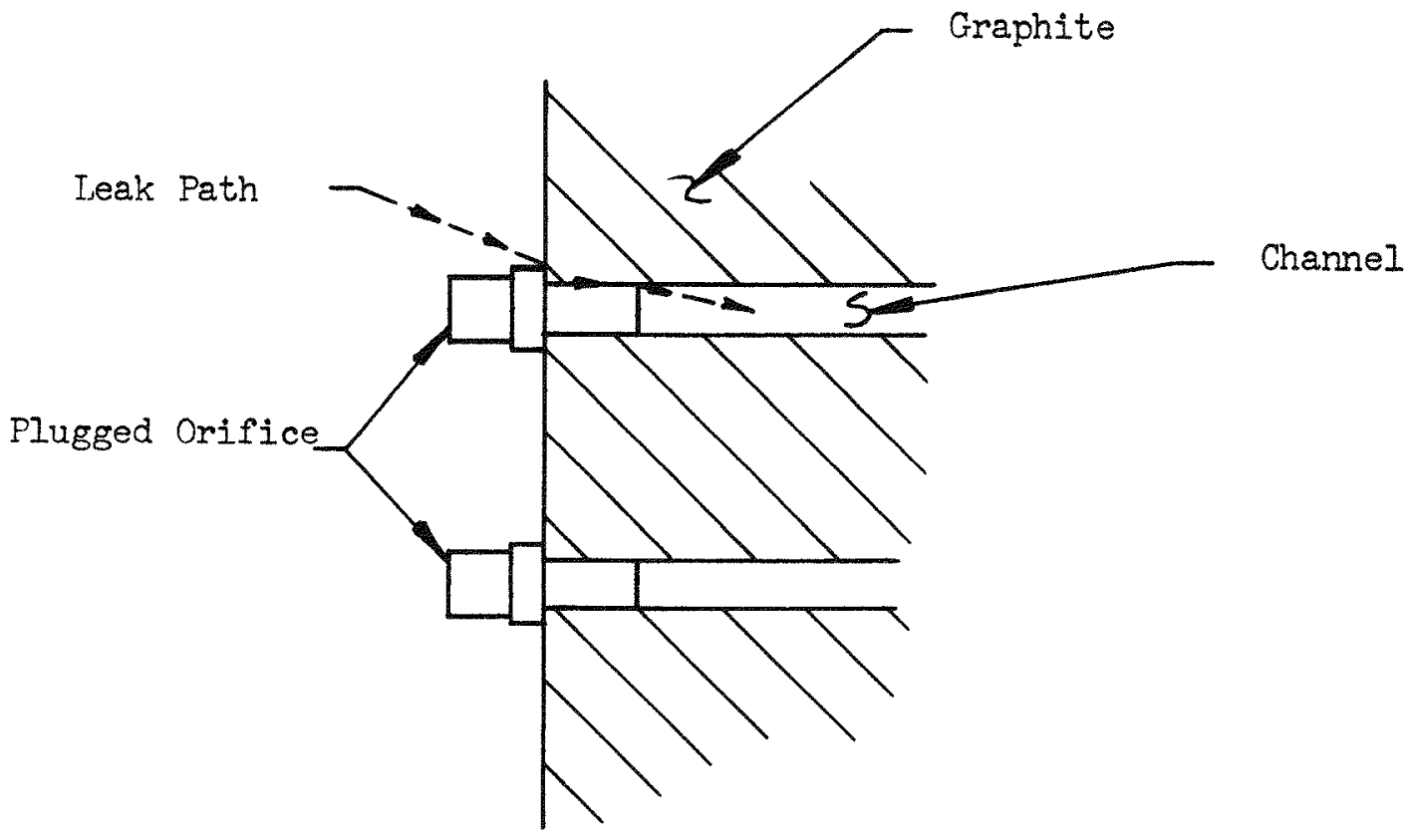

Typical Plugged Orifice Leak Flow Path

Cross Section Graphite Fuel

Element

Figure 6 
CQMEHEMTINL

RESTOHCTE- OHAIA

Afomic.Eneroy

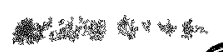

$$
\text { UANTronuclear }
$$

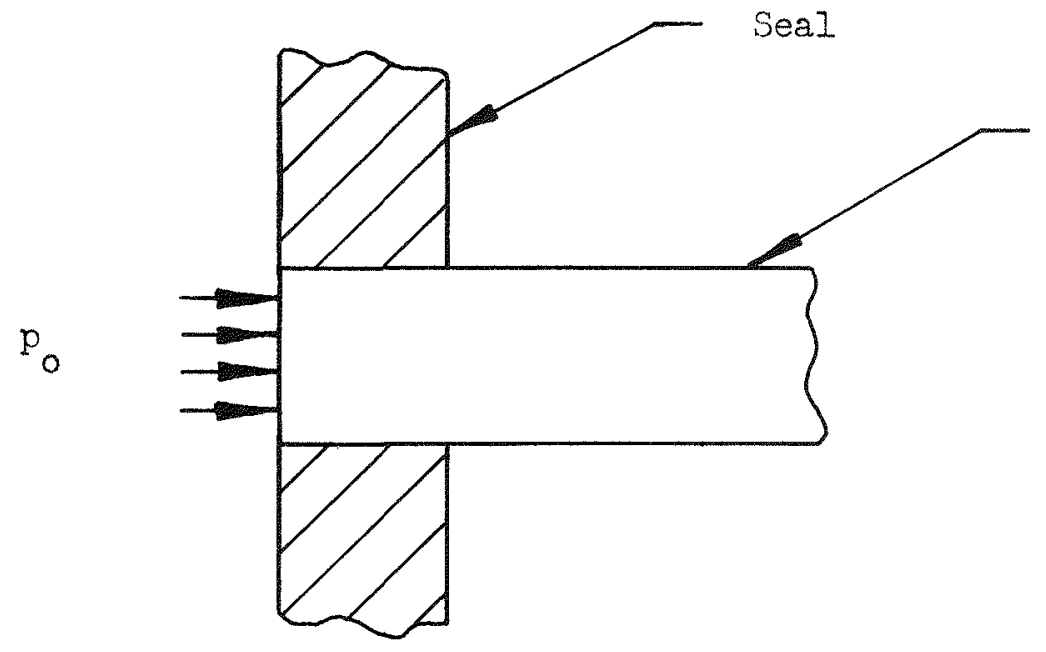

larch 20, 1064

Graphite Fuel Ilement

WANL Flement Sealing Arrangement

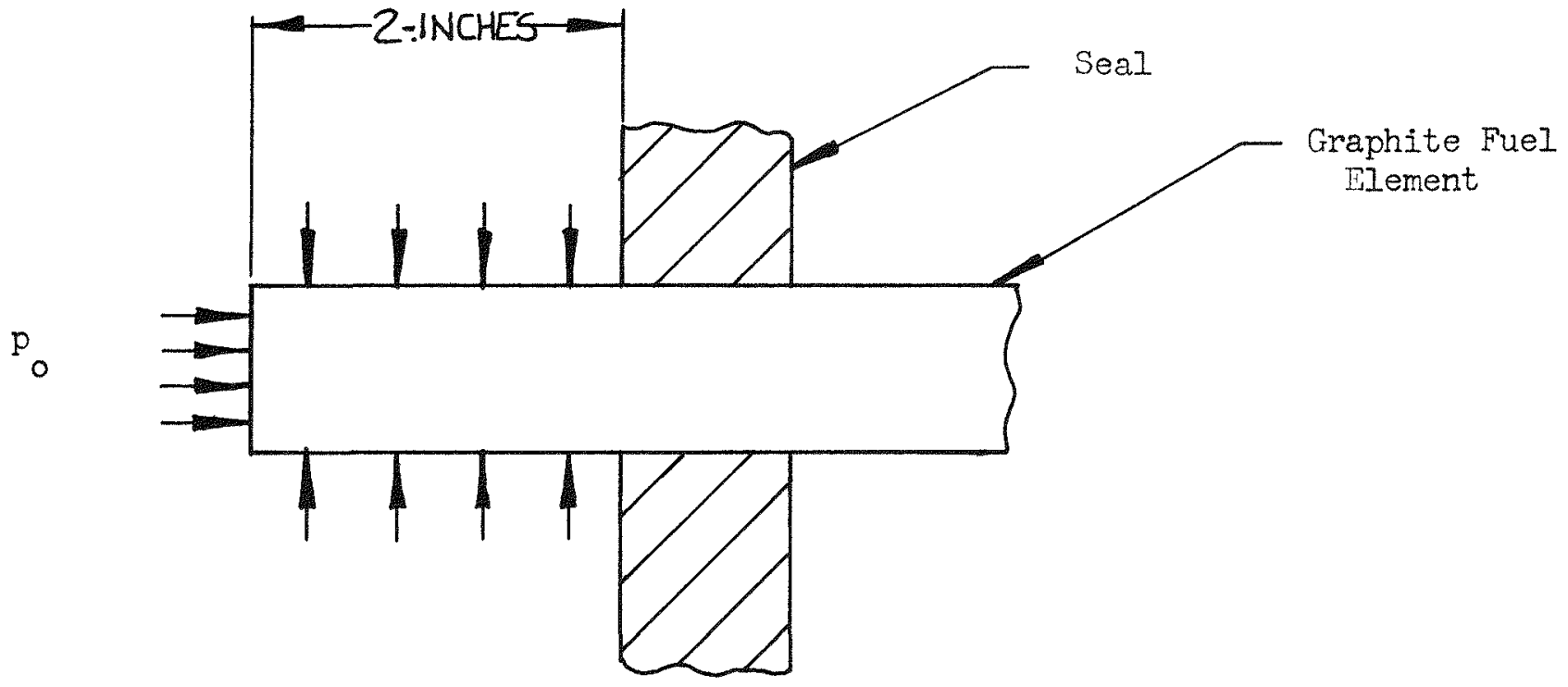

IASL Element Sealing Arrangement

Comparison of WANL and LASL

Graphite Fuel Flement Sealing Arrangement

Figure 7

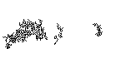

$18 x^{*}$ 

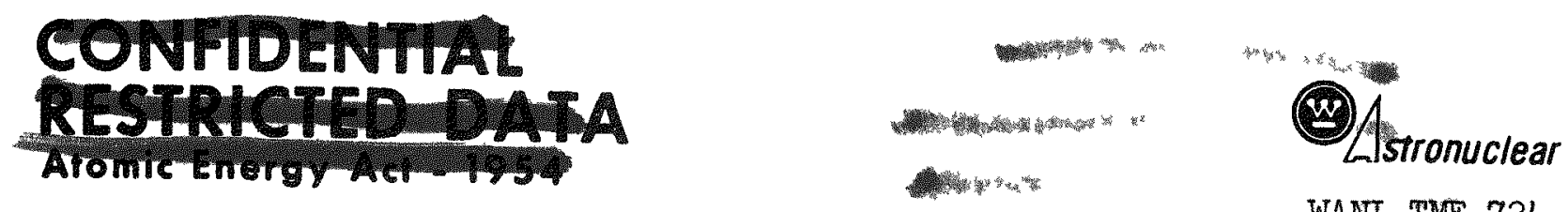

WANL-TME-724

March 20, 1964

b. Discussions with LASL indicated that quantitative leak checks to determine the effectiveness of the orifice-element seal were not made, thereby giving IASI a leak condition that was essentialiy random whereas WANL's was controlled. WANL's first experience in this area indicated that orifice-element seals either sealed properly or leaked excessively. 


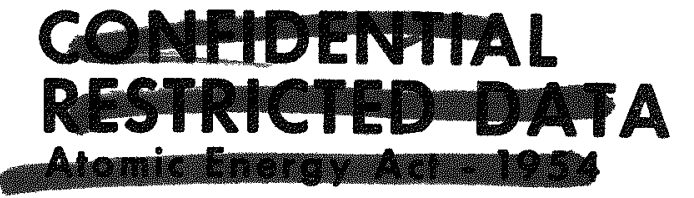

का

4.

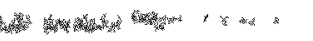

WANL-TME-724

March 20, 1964

\section{APPENDIX A}

\section{NOTATION}

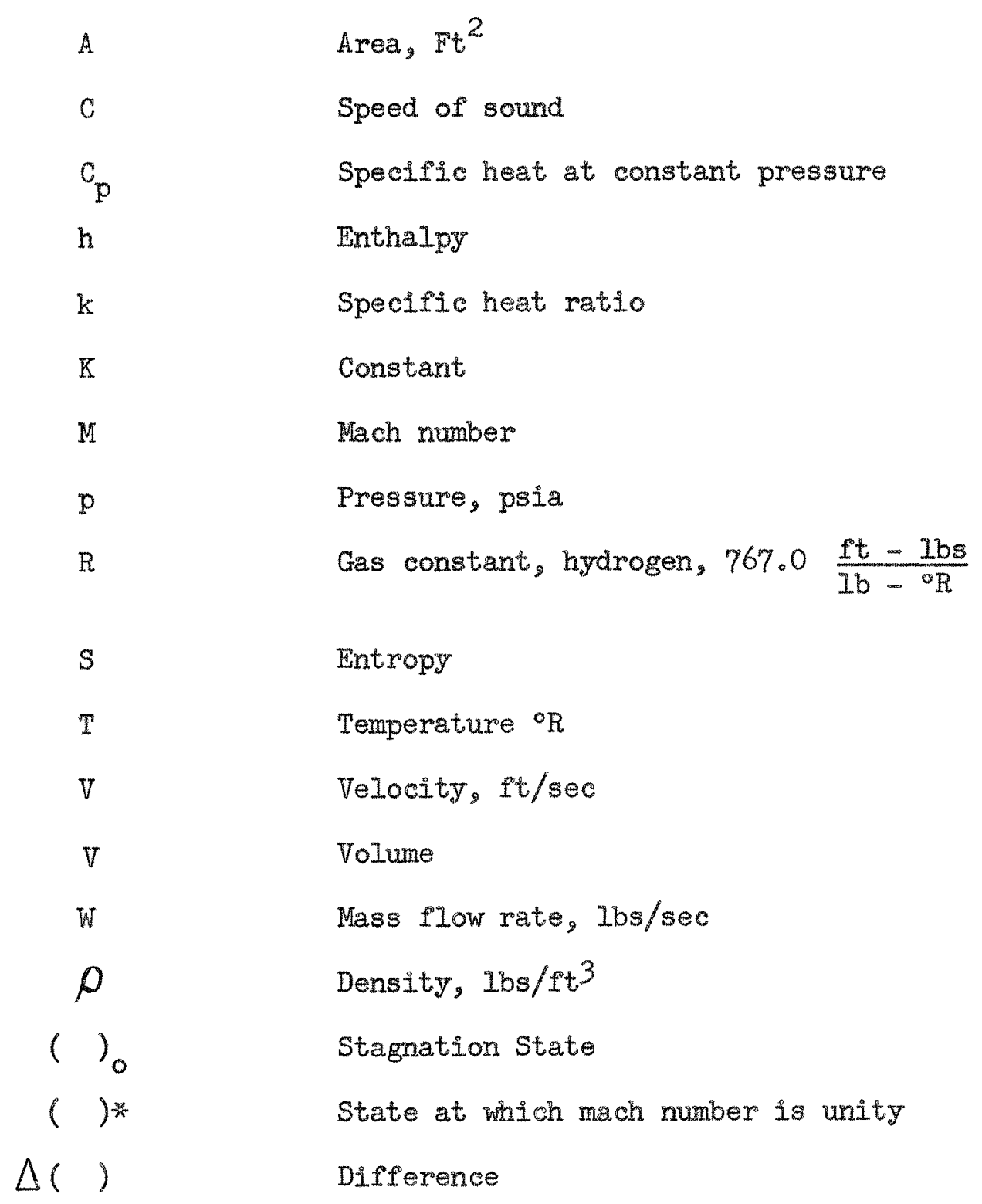



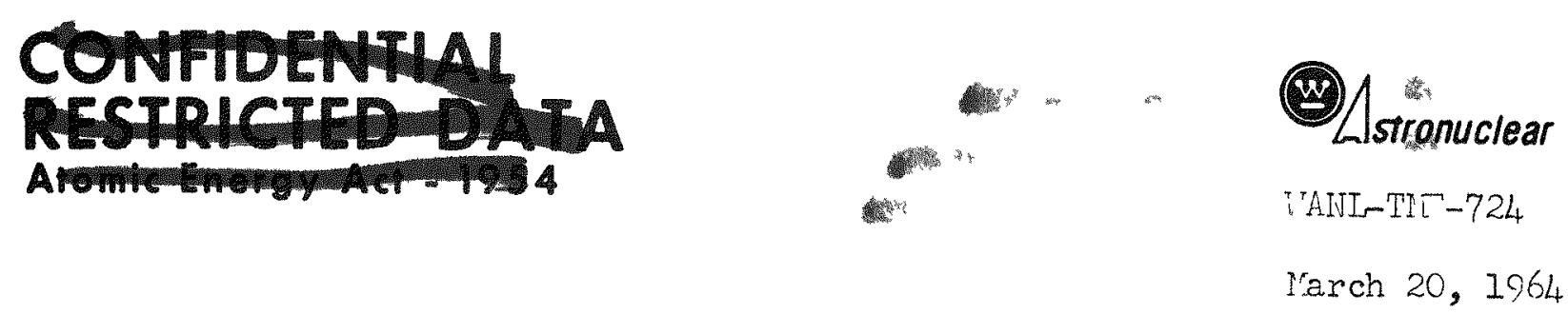

APPENDIX B
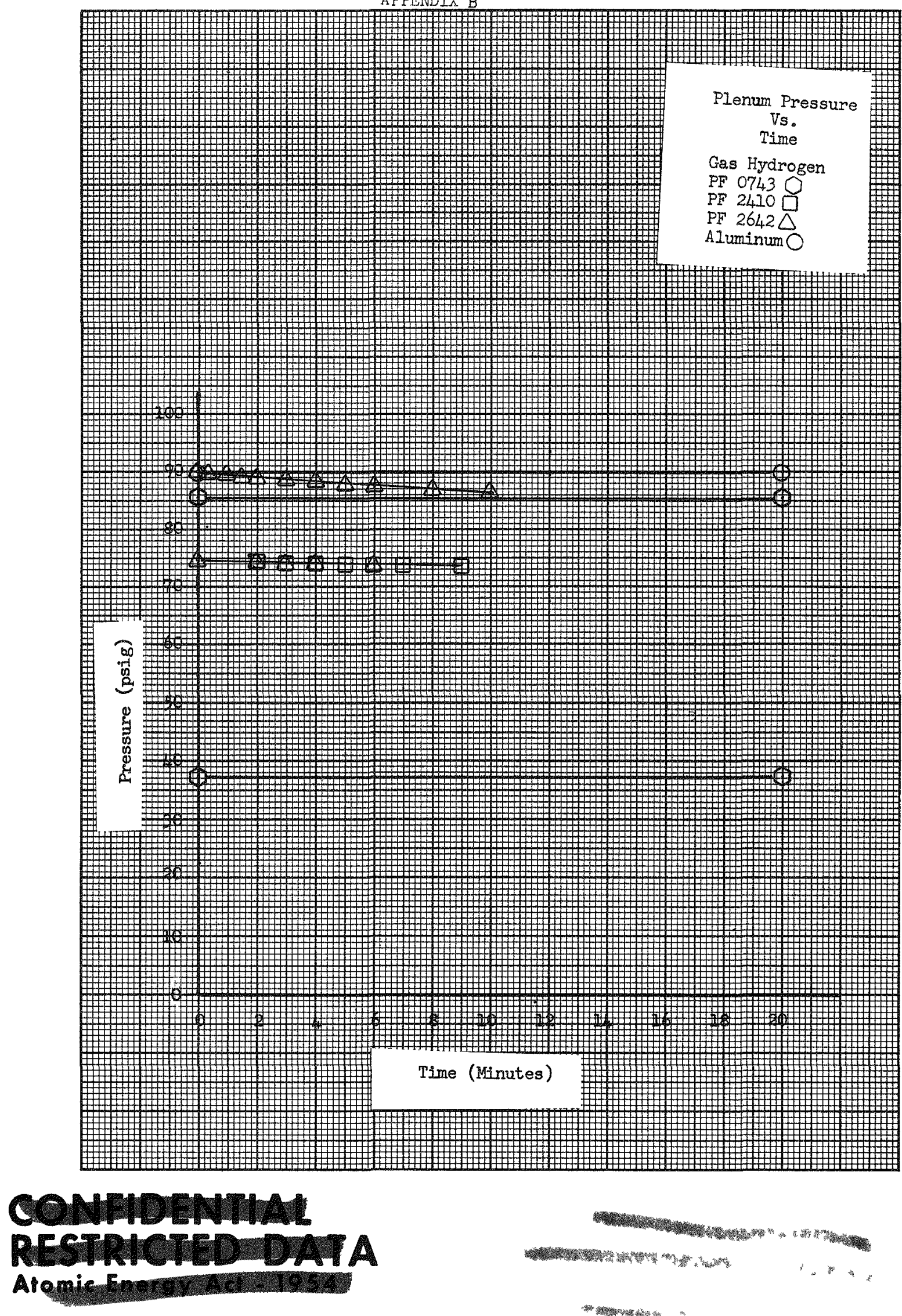


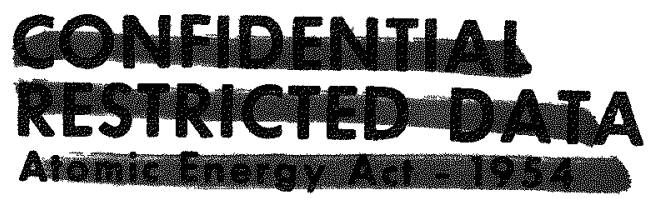

\section{APPENDIX C}

Consider the flow of a fluid through a passage of varying cross section ${ }^{\text {I. }}$ Treating the fluid as a perfect gas we have,

$$
\Delta h=c_{p} \Delta \mathrm{T}
$$

and

$$
h_{0}-h=C_{p}\left(T_{0}-T\right)
$$

Also

$$
C_{p}=\frac{k}{k-1} R
$$

As a result of the First Law of Thermodynamies

$$
h_{0}=h+\frac{v^{2}}{2}
$$

Substituting equations (1) and (2) in equation (3)

$$
\begin{gathered}
\frac{k}{k-1} R\left(T_{0}-T\right)=\frac{V^{2}}{2} \\
V=\sqrt{\frac{2 k}{k-1} R\left(T_{0}-T\right)}
\end{gathered}
$$

${ }^{I}$ one of the underlying conditions of this development is that the fractional rate of change of area with respect to distance along the axis is small. This is not strictly true in this experiment. It will be assumed that flow streamiines in the vicinty of the orificeelement seal defect will accommodate themselves such that a uniform convergent flow is essentially achieved. 

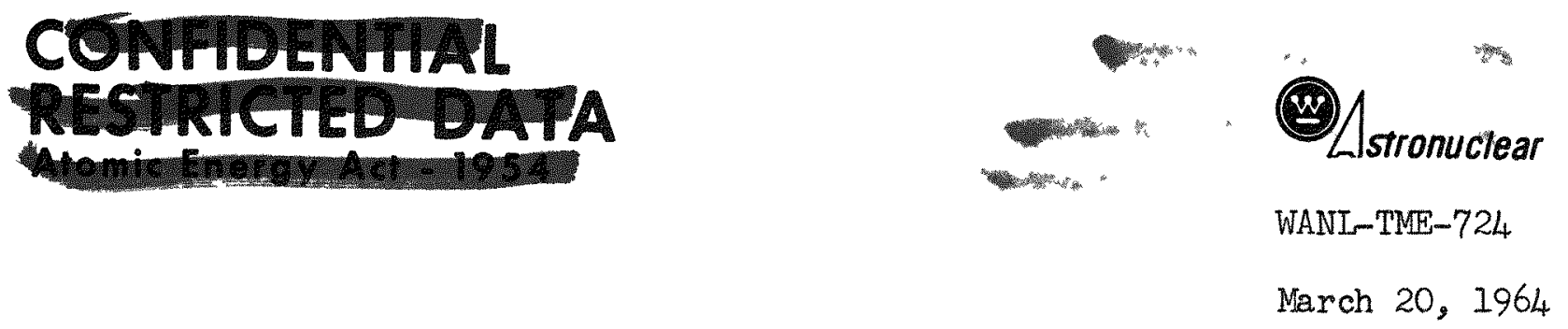

From this it can be seen that for a fixed stagnation temperature, all states with the same temperature, have the same velocity. Referring to the Temperature - Entropy diagram of Figure 8, lines of constant velocity are horizontal, and the vertical distance between $\mathrm{T}_{0}$ and $\mathrm{T}$ is proportional to the square of the velocity. It is immediately evident that any irreversibilities will decrease flow velocity and hence mass flow rate. It is, therefore, evident that the assumption of an isentropic process will lead to the calculation of leakage rates somewhat higher than thoseactually expected.

The derivation of the relation between mass flow rate and the pressure drop across the core is made by starting with the following rearrangement of the equation of continuity.

$$
\begin{aligned}
& \frac{W}{A}=\rho V=\frac{p}{R T} V \\
& \frac{W}{A}=\frac{p V}{\sqrt{k R T}} \sqrt{\frac{k}{R}} \sqrt{\frac{T_{0}}{T}} \frac{1}{\sqrt{T_{o}}}
\end{aligned}
$$

Rewritting equation (4)

$$
\frac{T_{0}}{T}=1+\left[\frac{k-1}{2}\right]\left[\frac{V^{2}}{k R T}\right]
$$

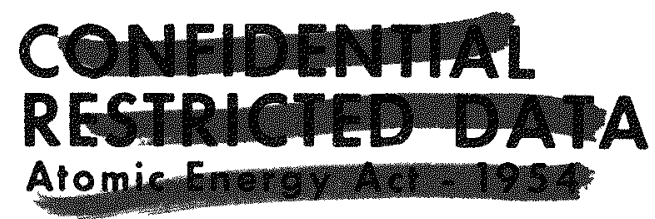




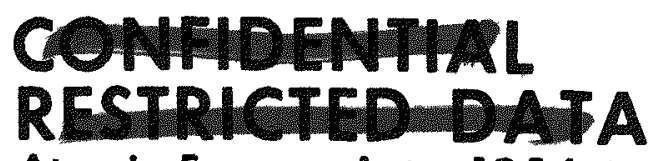

Atomic.Enorgy Anterias
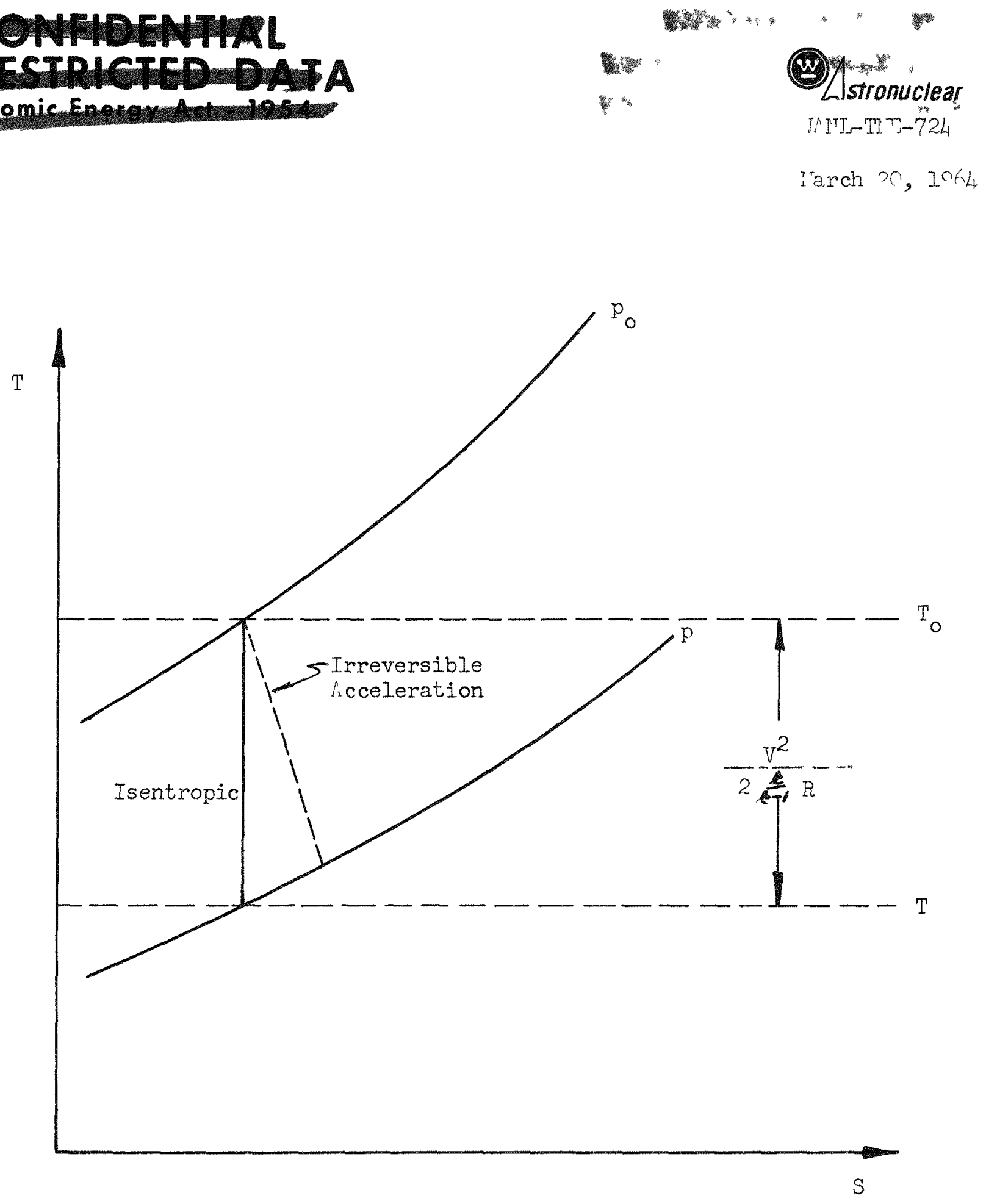

Flow Process on Terperature - Tntropy Diagram ᄀisure 


\section{CONFIDENTHAL RESTRICTED DATA \\ Atomich lanargen}

Recalling that

and

$$
\begin{aligned}
& M=\frac{V}{C} \\
& C=\sqrt{k R T}
\end{aligned}
$$

substituting in equation (5)

$$
\frac{W}{A}=\frac{p}{\sqrt{T_{0}}} \sqrt{\frac{k}{R}} M \sqrt{I+\frac{k-1}{2} M^{2}}
$$

The relation between pressure and temperature for an isentropic process of a perfect gas is

$$
\left(\frac{p}{p}\right)^{\frac{k-1}{k}}=\frac{T}{T_{0}}
$$

and substituting in equation (6) we have

$$
\frac{p_{0}}{p}=\left[\begin{array}{ll}
1+\frac{k-1}{2} & 2
\end{array}\right]^{\frac{k}{k-1}}
$$

Equation (7) then reduces to

$$
\frac{W}{A}=\sqrt{\frac{2 k}{k-1}} \frac{p_{0}}{\sqrt{R T_{0}}} \sqrt{\left.\frac{p}{p_{0}}\right)^{2 / k}-\left(\frac{p}{p_{0}}\right)^{\frac{k+1}{k}}}
$$




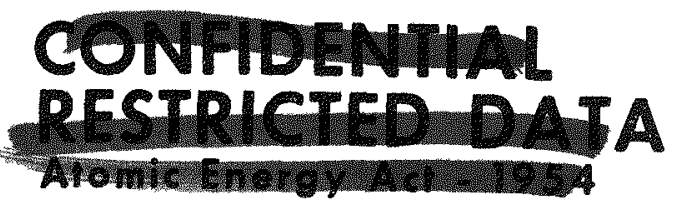

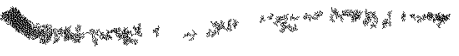

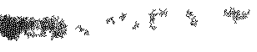

14.

stronuclear

WANI-TME-724

March 20,1964

and

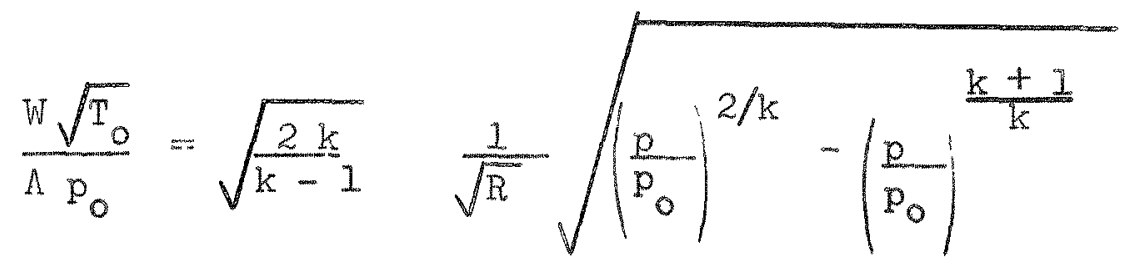

For hydrogen

$$
\begin{aligned}
& R=767.0 \frac{f t-1 b s}{1 b-{ }^{\circ} R} \\
& k=1.41
\end{aligned}
$$

and

$$
\frac{W \sqrt{T_{0}}}{A p_{0}}=.532 \sqrt{\left(\frac{p}{p_{0}}\right)^{1.419}-\left(\frac{p_{0}}{p_{0}}\right)^{1.71}}
$$

A choked flow condition exists for pressure ratios below the critical value. This value may be found by setting the Mach number equal to one in equation ( 8 ).

$$
\begin{aligned}
& \frac{p^{*}}{p_{0}}=\left[1+\frac{k-1}{2}\right]^{\frac{k}{k-1}} \\
& \frac{p^{*}}{p_{0}}=\left[\frac{k+1}{2}\right]^{\frac{k}{k-1}}
\end{aligned}
$$

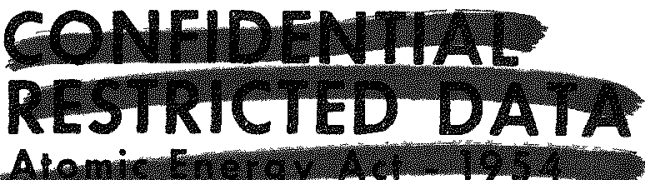




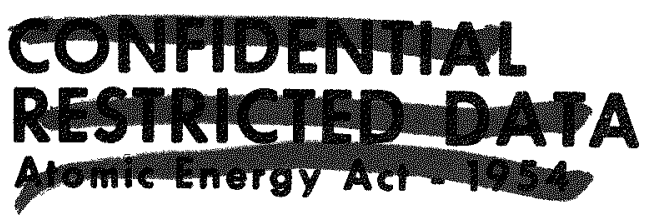

Controentat

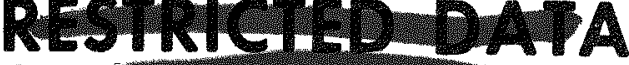

Alowichergy Act
$-2 x+4=2$

政

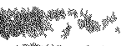

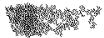

(w)

Lstronuclear

WANI-TME-724

March 20, 1964

For hydrogen

$$
\frac{p^{*}}{p_{0}}=0.526
$$

The mass flow rate under choked flow conditions is found by setting the pressure ratio to its critical value.

For hydrogen

$$
\frac{W \sqrt{T_{0}}}{A p_{0}}=.1391
$$

GONEIDENTFAL

RESTFVTED

Atomic- Energym Actser 195

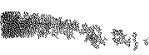

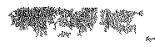



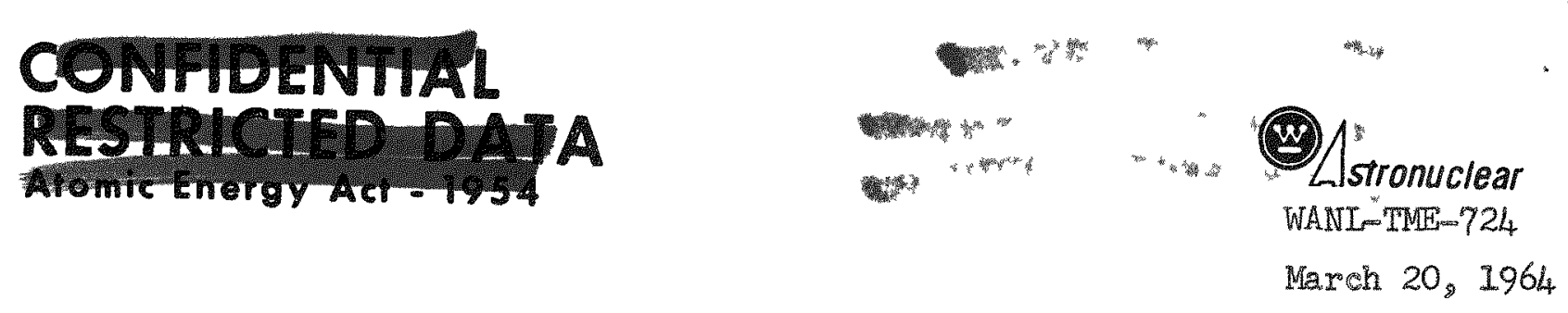

\section{APPENDIX D:}

The ND 20701 core when tested will provide data for the evaluation of component leakage flows, I.e., lateral support and inter-element. This requires the sealing of all fuel element coolant channels. It is essential that all plugged channels be tested and moreover that those channels winch are leaking within the acceptable limit must have their leakage flows measured and recorded in order to fulfill post-operative test data analysis. Silastic RTV 891 , a room temperature curing silicone rubber adhesive, was found to have the best combination of properties for the installation of stainless steel orifices into graphite fuel elements. Leak testing of the orificed elements Involves basically the placement of an element into the leak test fixture such that the inlet end of the element protrudes into a small chamber. A pressure differential of 70 psig is maintained across the orifices plugs. Leakage rate is then calculated from a measurement of transient pressure rise in the channel downstream of the orifice using helium. This volume becomes enclosed when attachment of a pressure gage is made. This method of leakage flow determination by means of employing a transient measurement readily provides for the evaluation of a steady state leakage flow.

The implementation of leak testing was initiated during the beginning stages of ND 20701 core assembly when a leak test fixture was made available. The limits of plug leakage acceptability for ND 20701 were specified and called for a leak test time duration of 5 seconds per channel with a maximum allowable pressure rise of 0.7 psi in this time interval. Elements with plugs having leakage in excess of this ralue are rejected for resealing.

*The following is an abstraction of appropriate parts of WANI-TM-966.
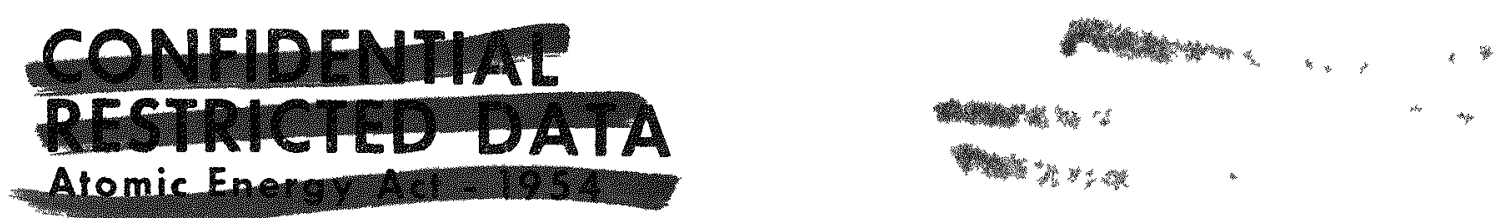

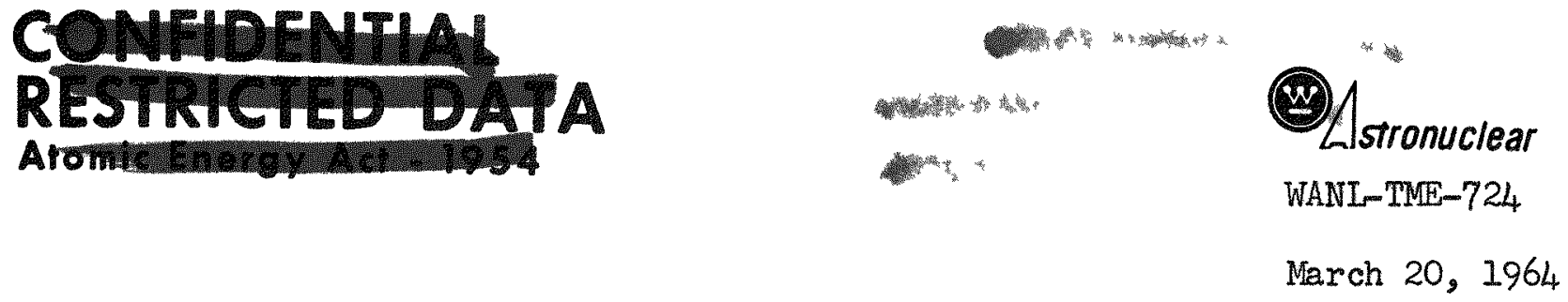

At the outset of ND 20701 element leak testing, 50\% of the elements tested had an average of four channels per element which were leaking excessively. Preliminary calculations using this statistical leakage, predicted that such leakage if permitted would have seriously impeded the achievement of the G-3 test objective from the standpoint of test facility hydrogen supply; and moreover, the assessment of inter-element flow characteristics would have been completely obscured.

In view of these initial leak-test results, disassembly was carried out for the 125 assembled ND 20701 clusters whose elements did not undergo leak test acceptability. These were then leak tested.

The high percentage of leakage was attributed to the following factors:

1. Adaptation of adhesive application to production techniques for which acceptability was proved out under controlled laboratory conditions only. Furthermore a wire applicator was used instead of a flat surface spatula type of applicator as called for in the research report.

2. Silastic RTV 891 when exposed to atmospheric conditions was found to develop a surface film. This film when deposited on the orifice during application could inhibit proper sealing.

3. Accidental mishandiing during the curing time interval.

4. Lower conditions of relative humidity which gives rise to a longer curing time in order to achieve the required sealing characteristics.

5. Quality control surveillance of orifice installation.

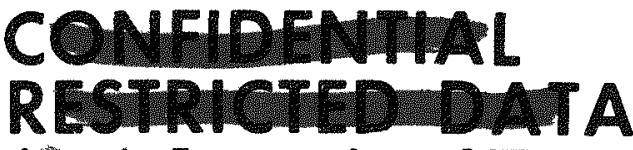



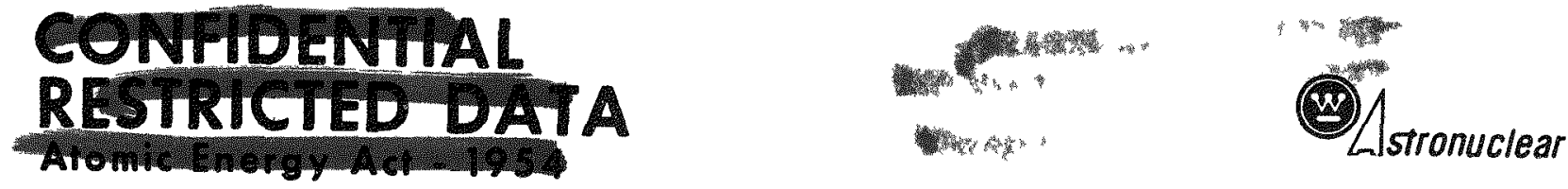

WANI $-1 M E-724$

March 20,1964

Corrective action was subsequently taken on the achievement of an acceptable fix on the repair of leaking plugs.

The adopted procedure consisted of removing the leaking plug and inserting a new plug by using another method of applying the adhesive. This new method consisted of taking the shank of the plug and immersing It into the adhesive. Then immediately, the plug was inserted into the channel of the plug at which time it was rotated in the installation to achieve effective wetting of the graphite surface.

An assessment was made of a possible degradation of adhesive characteristics with time. In this regard seventeen elements were selected which had been leak tested and were again leak tested. The time span between leak tests for each of these ranged from $11 / 2$ to 2 weeks. All of these 17 elements again passed the leals test requirements.

To investigate the ability of the adhesive to withstand a vibrational environment, two clusters of elements from the ND 20701 core assembly were selected for vibrational testing. One cluster was mounted so that the vibrational excitation was imposed in the Iateral direction, $i_{0} e$ perpendicular to the channel flow, while the other cluster was subject to only one test in which the vibrational load was in the longitudinal direction, i.e. parallel to the channel flow. Three tests were carried out with the laterally vibrated cluster. These tests involved loads of 2,5 and 7 maximum average "g's, Each had a six minute test duration with an imposed vibration frequency of 30 cycles per second. The one test which was carried out with longitudal excitation was also six minutes in duration but had a vibration frequency of $100 \mathrm{cps}$ and subjected to a 5 -g maximum average vibrational load. Cluster disassembly and leak testing of the elements followed each of these
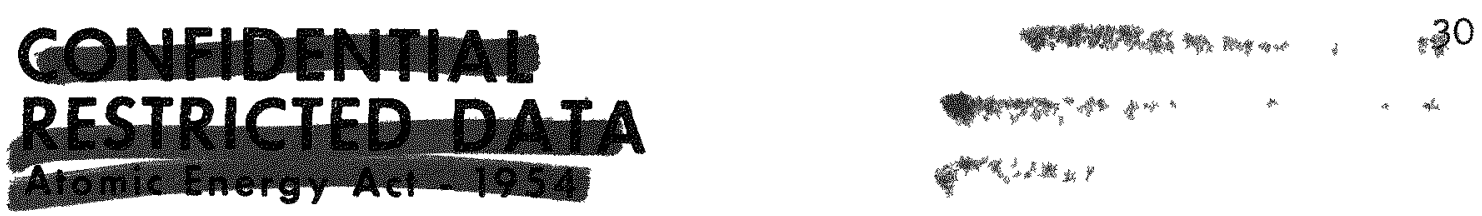
vibrational tests. Leak testing of the elements has been completed for both lateral and longitudinal vibration tests and the results show that all elements on each occasion met the leak test requirements. With reference to these lateral vibration tests, it is noteworthy that the resulting loads experienced at the ends of the cluster were more severe than the imposed loads at the local area near the holder mounting which was at the mid section of the cluster. The design of this particular holder was such that the flexural behavior during vibrational excitation gave rise to a whipping action at the ends of the cluster, thus subjecting the plug installations to a rather intense vibrational action. Despite the favorable results from these limited tests the level of confidence concerning seal integrity of the plugs during the operation of ND 20701 is unknown. In this regard all elements are to undergo plug leakage measurement after testing of the ND 20701 core build. 
CONFIDENTIAL

RESTRICTIED DATA

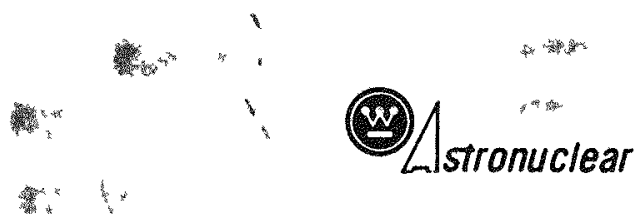

$7^{8}$

tis

Zstronuclear

CONFIDENTHAE

RESTRICTED DATA

*

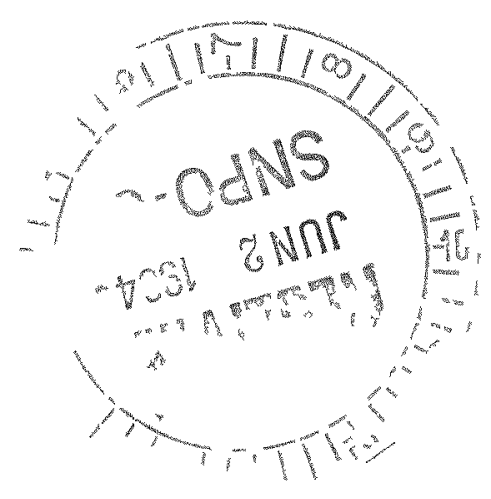

